\title{
Deep TCR repertoire sequencing reveals relative change in peanut specific clonotype in subjects undergoing rush oral immunotherapy
}

\author{
Philippe Bégin ${ }^{1,2^{*}}$, Kari C Nadeau ${ }^{1}$ \\ From Canadian Society of Allergy and Clinical Immunology Annual Scientific Meeting 2014 \\ Ottawa, ON, Canada. 23-26 October 2014
}

\section{Background}

Oral immunotherapy is an emerging therapy currently under investigation for the treatment of food allergy [1]. Underlying mechanisms are thought to involve a switch in the food specific $\mathrm{T}$ cell response from Th2 to either Th1, $\operatorname{Tr} 1$ and/or Treg. It is unknown whether this change in response results from re-education of existing pathological food-specific $T$ cells or from their replacement by new healthy $\mathrm{T}$ cells (change of guard hypothesis).

\section{Methods}

The objective was to evaluate the clonal distribution of peanut specific $T$ cell in subjects with peanut allergy and follow changes in clonotype with treatment using a high-throughput $\mathrm{T}$ cell receptor (TCR) sequencing platform. Peripheral blood mononuclear cells (PBMCs) from three subjects undergoing rush oral immunotherapy in a previous trial [2] and three control subjects on avoidance diet were cultured with peanut extract at baseline and at 9 and 18 months. Carboxyfluorescein succinimidyl ester (CFSE)-low peanut proliferating $\mathrm{T}$ cells were then isolated by fluorescence-activated cell sorting (FACS) and TCR analysis was performed.

\section{Results}

The CFSE-low proliferating fraction was found to be comprised of between 2000 and 12,000 different $\mathrm{T}$ cell clones. However, only between 15 and $25 \%$ of proliferating $\mathrm{T}$ cells (from 100-400 different clones) were consistently found at all three time points and probably represented true peanut-specific $\mathrm{T}$ cells. While the

\footnotetext{
* Correspondence: philippe.begin@umontreal.ca

'Department of Pediatrics, Stanford University, Stanford, California, 943055208, USA

Full list of author information is available at the end of the article
}

relative frequency of these peanut-specific clones was stable over time in subjects on avoidance diet $(R=0.633$ to 0.760 ), it was found to change in subjects undergoing oral immunotherapy ( $\mathrm{R}=0.123$ to 0.350 ), following two characteristic patterns.

\section{Conclusions}

Using a deep TCR sequencing platform, we found that only a fraction of CFSE-low peanut proliferating $\mathrm{T}$ cells were consistent in time and likely to represent true peanut specific $\mathrm{T}$ cells. Oral immunotherapy was associated with changes in relative frequency of clones within this fraction, which would support the change of guard hypothesis.

\section{Acknowledgements}

P. Bégin was supported by AllerGen NCE Inc. (the Allergy, Gene and Environment Network), a member of the Networks of Centre of Excellence Canada program.

\section{Authors' details}

'Department of Pediatrics, Stanford University, Stanford, California, 943055208, USA. ²Department of Medicine, University of Montreal, Montreal, Quebec, H3A 1A1, Canada.

Published: 18 December 2014

\section{References}

1. Bégin P, Chinthrajah RS, Nadeau KC: Oral immunotherapy for the treatment of food allergy. Hum Vaccin Immunother 2014, 10:8.

2. Bégin P, Dominguez T, Wilson SP, Bacal L, Mehrotra A, Kausch B, Trela A, Tavassoli M, Hoyte E, O'Riordan G, Blakemore A, Seki S, Hamilton RG, Nadeau KC: Phase 1 results of safety and tolerability in a rush oral immunotherapy protocol to multiple foods using Omalizumab. Allergy, Asthma \& Clinical Immunology 2014, 10:7.

doi:10.1186/1710-1492-10-S2-A53

Cite this article as: Bégin and Nadeau: Deep TCR repertoire sequencing reveals relative change in peanut specific clonotype in subjects undergoing rush oral immunotherapy. Allergy, Asthma and Clinical Immunology 2014 10(Suppl 2):A53. 